Int. J. Electrochem. Sci., 15 (2020) 9013 - 9023

\title{
Study on the Application of Carbon-coated Copper Foil as Negative Current Collector for Silicon-based Lithium-ion Batteries
}

\author{
Xiaohui Shen*, Le Shao, Zhanyuan Tian, Zhaowen Hu, Guolin Cao \\ Shaanxi Coal Chemical Industry Technology Research Institute Co., Ltd., Xi'an 710065, Shaanxi, \\ China \\ *E-mail: shenhui06@163.com
}

doi: $10.20964 / 2020.09 .25$

Received: 6 April 2020 / Accepted: 1 June 2020 / Published: 10 August 2020

$\mathrm{LiNi}_{0.8} \mathrm{Co}_{0.1} \mathrm{Mn}_{0.1} \mathrm{O}_{2}(\mathrm{NCM} 811) / \mathrm{SiO}_{\mathrm{x}}-\mathrm{Graphite}(\mathrm{SiO}-\mathrm{C})$ cell is one of the most potential battery systems with high specific capacity, however, it is difficult to improve its poor cycling performance in practical application. A carbon coated copper foil severed as negative current collector is developed and the effect of conductive carbon film on silicon-based negative electrodes is studied. The main properties of NCM811/SiO-C pouch cells with 9.5 Ah are also compared by using bare copper foil and carbon coated copper foil. The results show that the using of carbon coated copper foil current collector have favorable impact on the rate performance of batteries in particular at higher rates, even can obviously improve the cohesiveness between the anode powder and the current collector, boosting the cycle life. The capacity retention of the batteries with carbon coated copper foil after 300 cycles at $1 \mathrm{C}$ rate is $89.5 \%$, increasing by $5.2 \%$ compared with the batteries with bare copper foil.

Keywords: carbon coated copper foil; pouch battery; rate performance; cycle life; capacity retention

\section{$\underline{\text { FULL TEXT }}$}

(C) 2020 The Authors. Published by ESG (www.electrochemsci.org). This article is an open access article distributed under the terms and conditions of the Creative Commons Attribution license (http://creativecommons.org/licenses/by/4.0/). 